\title{
EFEITOS DO DISCURSO DAS NOVAS TECNOLOGIAS NA CONSTITUIÇÃO IDENTITÁRIA DO PROFESSOR DE LÍNGUAS ${ }^{1}$
}

\author{
Carla Nunes Vieira Tavares - Professora no curso de Letras - Licenciatura: Inglês e Literaturas - da Universidade Federal de \\ Uberlândia - UFU; Doutora em Linguística Aplicada pela UNICAMP e em Ciências da Linguagem pela Université de Franche- \\ Conté - França; Coordena o projeto de pesquisa "Incidências subjetivas no ensino-aprendizagem de línguas"; Pesquisadora do \\ Grupo de Pesquisa e Estudos sobre Linguagem e Subjetividade (GELS) - cadastrado no CNPq. \\ E-mail: $\underline{\text { carla.tav@uol.com.br }}$
}

Lucas Araujo Chagas - Graduando em Letras pela Universidade Federal de Uberlândia com mobilidade estudantil internacional na Université Paul Verlaine - Metz/França; Desenvolveu PIBIC/CNPq com a temática "O uso da internet no ensino de língua inglesa e suas contribuições para a inclusão social de alunos de escolas públicas”, sob orientação do Prof. Dr. William M. Tagata; Atua como estudante pesquisador do grupo de pesquisa "Letramentos e multiletramentos no ensino de línguas", da USP.

E-mail: chagas.luca@gmail.com

\begin{abstract}
Resumo
Observa-se no discurso pedagógico e acadêmico uma grande ênfase à relevância das novas tecnologias no contexto educacional. Ao considerar a valorização atribuída pela sociedade a tudo que é inovador e a constante reformulação pela qual passa o conhecimento na sociedade da informação, tanto a incorporação das novas tecnologias ao ambiente educativo como as políticas educacionais voltadas para a inclusão digital parecem ser plenamente justificáveis. Este artigo, porém, pretende problematizar os desdobramentos desse discurso aparentemente inquestionável para a constituição identitária do professor, em especial, de línguas, com base no escopo teórico-metodológico dos estudos discursivos de linha francesa. Para tanto, contrastamos a noção de identidade versus as análises de um excerto de texto publicitário e de algumas sequências discursivas provenientes do corpus do trabalho de Tavares (2010). Por fim, concluímos este trabalho com algumas ponderações sobre como a identidade do professor pode sofrer desestabilizações em função da interpelação do discurso das novas tecnologias.
\end{abstract}

\begin{abstract}
In the pedagogical and academic discourses a great emphasis has been given to the relevance of the new technologies in the educational context. Considering the value the society attributes to innovation and the frequent reformulation knowledge goes by in the society of information, the incorporation of the new technologies to the educational environment and the educational policy aimed at digital inclusion seem to be fully justified. In this article, however, we will problematize the consequences of this discourse - apparently unquestionable - to teacher's identity, in special, language teachers. In order to do so, we discuss the notion of identity and the results of the analysis of a publicity text, as well as some discursive sequences from the corpus of Tavares (2010). We will conclude with some reflections about how language teacher's identity can suffer destabilizations by the interpellation of the discourse of new technologies.
\end{abstract}

\section{Introdução}

Observa-se no discurso pedagógico e acadêmico uma ênfase à relevância de recursos eletrônicos, informáticos e midiáticos - conjunto entendido aqui como novas tecnologias - no contexto educacional. Um breve exame de alguns artigos sobre o tema (Menezes de Souza \& Monte Mór, 2006; Buzato, 2007) aponta que a adoção de novas 
tecnologias visa, por um lado, aproximar o ensino-aprendizagem das exigências de constante atualização e modernização da sociedade atual, desenvolver a autonomia do estudante, otimizar o acesso à informação e, pressupostamente, ao conhecimento. Por outro lado, no que se concerne à formação de professores, a introdução de novas tecnologias na educação promete agilizar o processo educacional por disponibilizar inúmeras ferramentas que são nomeadas como fundamentais à prática do professor e incentivar mudanças nos métodos de trabalho, dentre outras possibilidades. A disposição dessa escala de funções atribuídas às novas tecnologias no contexto educacional constitui um discurso referido neste trabalho como o "discurso das novas tecnologias", que apregoa ter como objetivo mais amplo a formação de cidadãos preparados para lidar com a globalização.

A inserção das novas tecnologias na educação, além de constituir um discurso próprio, nos últimos anos tem materializado a inclusão da escola na lógica de redes, estendendo a ela os alardeados benefícios da penetrabilidade da informação e as decorrentes vantagens da sociedade da informação, consequência dos processos globalizantes da contemporaneidade (Castells, 2000).

Ao fazermos considerações à valorização atribuída pela sociedade a tudo que é inovador e à constante reformulação pelo qual passa o conhecimento na sociedade da informação, a incorporação das novas tecnologias ao ambiente educativo e as políticas educacionais voltadas para a inclusão digital parecem ser plenamente justificáveis. Entretanto, este artigo pretende problematizar os desdobramentos desse discurso aparentemente inquestionável para a constituição identitária do professor, em especial, de línguas. Quer nos parecer que as mudanças decorrentes do rápido e contínuo avanço tecnológico, bem como a exigência da incorporação das novas tecnologias na educação constituem um dos fatores responsáveis por fomentar embates com a identidade profissional do professor.

Assim sendo, a incidência do discurso das novas tecnologias sobre a constituição identitária do professor de línguas será problematizada a partir de uma perspectiva teórico-metodológica ancorada nos estudos sobre o discurso, em especial de autores como Foucault e Coracini. Inicialmente traçaremos um breve histórico sobre a crescente adoção das tecnologias no campo da educação, aproximando-o das demandas da sociedade da informação. Em seguida, discutiremos a noção de identidade e os resultados de análise de um excerto de texto publicitário e de algumas sequências discursivas provenientes do corpus do trabalho de Tavares $(2010)^{2}$. Concluiremos com algumas ponderações sobre como a identidade do professor pode sofrer desestabilizações em função da interpelação do discurso das novas tecnologias.

\section{1) As novas tecnologias no ensino de línguas}


Entendemos, juntamente com Foucault (2005), que toda e qualquer verdade não é encontrada e sim produzida. Além disso, a verdade existe como um saber dentro de um discurso particular e está amarrada ao poder. O poder, por sua vez, é entendido como uma questão de relações complexas em vez de uma propriedade inerente a um indivíduo ou classes particulares.

Quando falamos em educação voltada para as novas tecnologias é comum encontrarmos que o discurso da globalização, enquanto "uma construção primordialmente ideológica" (Spargo, 2007, p. 19), estabelece verdades capazes de produzir efeitos de poder que provocam conformação, adestramento e sujeição de pessoas.

A introdução das novas tecnologias no ensino de línguas tem seu início com mais precisão durante a Segunda Guerra Mundial, período no qual o sistema capitalista globalizado ganha força e começa a se espalhar pelo mundo. Nesse mesmo período, aparatos tecnológicos, de forma indireta, ganharam espaço na sociedade, que, ao fazer deles bens de consumo, outorgaram-lhes novas funções. As patentes desses maquinários perceberam que era possível aprimorá-los e adaptá-los às novas necessidades dos consumidores provocando o estabelecimento de um mercado consumidor sempre ativo, visto que a cada nova necessidade seria produzido um novo equipamento.

Com a evolução acelerada da tecnologia e dos recursos digitais apropriados para se tornarem bens de consumo durante a Guerra Fria, novos equipamentos foram sendo introduzidos no ensino de línguas e também na educação básica. No que se refere à utilização das novas tecnologias no ensino de idiomas, as fitas cassetes e, posteriormente, os vídeos cassetes são exemplos de recursos considerados revolucionários, porque possibilitavam um contato mais direto com a língua e a cultura estrangeira.

Com as mudanças nos hábitos de vida causados pela invasão das novas tecnologias na esfera cotidiana, os professores depararam-se com a necessidade de (re)elaborar suas perspectivas educacionais e (re)pensar as novas práticas resultantes da invasão tecnológica no ambiente pedagógico. Além disso, a crescente demanda de atualização às inovações tecnológicas tem feito com que professores se engajem em cursos de qualificação tecnológica e em programas de formação continuada, a fim de se manterem qualificados com o que há de novo e moderno no setor educacional.

$\mathrm{O}$ conjunto de fatores desdobrados pela educação globalizada e digitalizada engendra, portanto, outros papéis, impondo desafios e conflitos para o professor. Este, na busca de preservar seu espaço no discurso pedagógico, muitas vezes acaba por se sujeitar a determinações de forças de poder, no caso, a força do discurso da globalização e da exigência do mercado. Os resultados da análise do corpus deste trabalho apontam que o discurso das novas tecnologias na educação traz injunções da globalização e do mercantilismo, resultando na imputação de modos de subjetivação de professores de línguas estrangeiras, de forma a produzir identidades conformadas às demandas do 
mercado, tônica da sociedade globalizada. Porém, antes de abordar essa questão, cumpre circunscrever o que entendemos como identidade.

\section{2) A constituição identitária do professor de línguas}

A noção de identidade, neste trabalho, é deslocada de algo estável e socialmente determinado para ser encarada como um construto discursivo múltiplo, desestabilizado, contraditório, incoerente, fragmentado, em constante construção, nos moldes do momento sócio-histórico em que vivemos (Bauman, 2005). Em outras palavras, a constituição identitária é diretamente afetada pela sociedade da informação, um dos frutos da rarefação dos referenciais, da plasticidade das relações, da flexibilização e relativização das verdades, do rápido desenvolvimento tecnológico e das demandas da globalização, características de uma era pós-moderna ou informacional, como prefere Castells (2000). Entretanto, defendemos que esse processo é atravessado pela singularidade pela qual cada um irá vivenciá-lo.

Por essa razão, preferimos a expressão "constituição identitária" para nos referir à identidade. A expressão enfatiza a mobilidade, multiplicidade e heterogeneidade que constituem a contínua (re)construção da ilusória síntese imagética que nos identifica como seres humanos e nos singulariza dentro dessa espécie (Tavares, 2010).

No que concerne à constituição identitária profissional, entendemos que a imagem construída de cada ofício, por um lado, reflete as expectativas advindas das demandas sociais em relação ao desempenho e ao papel esperado daquele que o exerce. Pode-se dizer, portanto, que ela remete à ordem de um ideal. Por outro lado, essa imagem é construída, também, a partir da instauração de uma possível (re)significação desse ideal, por meio das práticas sociais e da subjetivação ${ }^{3}$ por elas propiciada. Ou seja, o ideal sempre esbarra na contingência.

Posicionar-se socialmente enquanto professor de línguas, por conseguinte, implica identificar-se a traços de uma discursividade sobre o que é ser professor e o que é ensinar-aprender línguas, dentre outros, bem como apropriar-se dessa discursividade por meio de práticas de (re)significação.

Com base no peso que o discurso das novas tecnologias na educação vem assumindo, acreditamos que a constituição identitária do professor de línguas seja constituída, dentre outros elementos, das representações sobre as novas tecnologias e seu papel na educação e na prática de professores de línguas. Tais representações estão presentes no dizer de professores e no discurso midiático e constituirão os elementos que embasarão a análise da incidência do discurso das novas tecnologias na constituição identitária dos professores de línguas.

\section{3) As novas tecnologias como diferencial no discurso pedagógico}


Ao serem adaptadas pelas escolas, nos últimos anos, as novas tecnologias começaram a ganhar status, visto que davam uma boa aparência às salas de aula e também poderiam oferecer recursos que favoreceriam a educação. Ao analisarmos um texto publicitário de uma escola de idiomas nos deparamos com o seguinte discurso:

"Sintonizada com os mais recentes avanços tecnológicos e acadêmicos na área de ensino de línguas estrangeiras, a (NOME DA ESCOLA) disponibilizou aos seus alunos a lousa interativa, que permite transformar o antigo quadro branco num quadro digital ou num quadro interativo on-line.

Essa é a mais moderna e inovadora ferramenta educacional que tem como principal objetivo permitir que o aluno assimile de forma muito mais eficaz o conteúdo através de um novo conceito de interatividade.

A lousa digital funciona com softwares específicos e com uma caneta magnética que, com um número infinito de possibilidades e recursos, tornam as aulas mais dinâmicas, ilustradas e principalmente produtivas.

Além disso, conectamos em tempo real com escolas e alunos do mundo todo, o que permite que nossos alunos interajam com falantes nativos da mesma faixa etária durante as suas aulas, promovendo uma real exposição e prática da língua e tornando possível a convivência intercultural"4.

Nesse texto, verificamos que a lousa digital é apresentada como essencial para a aprendizagem do aluno, por meio da exacerbação do seu valor em detrimento de outros elementos do processo, sentido construído, principalmente, pela adjetivação. Percebemos na frase " (...) tornam as aulas mais dinâmicas, ilustradas e principalmente produtivas" o discurso da produtividade, que é indiretamente inserido na aprendizagem de línguas. Consequentemente, constrói-se o sentido de que o aprender está associado a produzir. O adjetivo "infinito" associado às possibilidades e recursos anunciados corrobora a representação de ausência de limites para o escopo de ação e alcance de resultados dessa tecnologia apresentada como inovadora. Observa-se, ainda, uma abertura do sentido pela distância do advérbio "mais" do adjetivo "produtivas", o que infere o sentido de ausência de produção antes da lousa digital. Semelhantemente percebe-se a valorização do novo como imperativo para o sucesso da aprendizagem, como a adjetivação conferida ao quadro branco e o verbo utilizado na oração: "transformar o antigo quadro branco num quadro digital ou num quadro interativo online".

Como na atualidade as escolas privadas e escolas de idiomas vivem uma nova ordem discursiva, em que a educação e o ensino se tornaram produto de venda, na tentativa de entregar a seus clientes (alunos) um produto que fora comprado, o discurso das escolas tem sido entremeado por inúmeros discursos de formações discursivas outras que acabam trazendo novos desafios e paradigmas. Estes acarretam mudanças na subjetividade e na discursividade do professor e do aluno, que passam a ser constantemente avaliados pelo seu desempenho (produtividade). Essas avaliações visam 
nada mais do que quantificar o ensino como um produto resultante de técnicas para mostrar ao cliente (aluno) o quanto ele está aprendendo, para quantificar o que ele comprou (Da Silva, 2011). Percebe-se, portanto, a incidência do discurso utilitarista alicerçado no neoliberalismo - no discurso do ensino-aprendizagem de línguas, construindo a representação de que antes do novo o processo de aprendizagem de línguas era menos eficaz ou até inviável. Esse discurso produz o sentido de anulação das ações educacionais que não se pautam pelo novo e pelo inovador, ignorando que a aprendizagem pode ocorrer independentemente das ferramentas que estão em jogo.

Nesse cenário, o professor deixa de exercer o papel de condutor do processo de ensino/aprendizagem e passa a ser um aplicador de técnicas. O processo de ensinoaprendizagem é reduzido à produção quantificada de conhecimento, o que não implica necessariamente em apreensão do mesmo. Note-se, a título de ilustração, a ausência de qualquer menção quanto aos professores no texto acima. A figura do professor, portanto, torna-se secundária em relação à tecnologia, ensejando àqueles que se posicionam como tal desafios quanto à constituição identitária profissional.

\section{4)A defasagem do professor em relação às novas tecnologias}

Uma representação recorrente no dizer dos docentes do corpus de Tavares (2010) é a de que o professor de língua estrangeira da escola pública e o ensino ali promovido estão aquém do esperado. Essa representação não é recente e já foi analisada sob diferentes aspectos por outros autores (Baghin-Sinelli, 2002; Grigoletto, 2003). Chamou a atenção, porém, o peso atribuído à tecnologia na construção de uma identidade de professor faltosa, como indiciado no excerto seguinte:

\section{$\mathrm{E} 01 \mathrm{DP} 2^{5}$}

$\mathrm{P}-\mathrm{E}$ você acha que você poderia fazer isso tudo falando em inglês?

$M-[\ldots]$ Eu acho que ainda não

$\mathrm{P}-$ Por quê?

M - Porque eu ainda não me sinto segura como professora/ assim/ ainda me falta bastante

$\mathrm{P}$ - E se você se sentisse/ você acha que conseguiria? Que isso é viável?

M - Não// Acho que ainda não/ o nosso aluno também não tá preparado ainda pra isso $\mathrm{P}-\mathrm{Tá}$

M - Eu ainda/ não sei/ eu acho ainda/ porque na escola de particular/ específico no curso de inglês/ você tem lá três horas pra trabalhar com o seu aluno/ que pode ser dividido em uma hora e meia e uma hora e meia ou no meu caso que eu fazia no sábado eu fazia três horas de uma vez com um intervalo um pouquinho maior pra não se tornar cansativo// Eles têm outros recursos né/ de computador né/ eh/ outros recursos// então/ fica ainda um tanto complicado porque na escola pública eh/ nem toda a escola tem uma sala de vídeo legal/ nem toda a escola tem um retroprojetor legal e então eu acho que ainda falta assim/ mecanismos de trabalho. 
Embora proclamasse ter um nível de inglês "pré-intermediário" (conforme relatado na entrevista), a professora $M$ não se considerava competente discursivamente na língua que ensinava, ainda que sua prática em sala de aula evidenciasse uma preocupação em promover atividades de leitura que mobilizassem uma certa discursividade na língua estrangeira.

Além da falta da língua, que poderia ser considerada como um dos fatores responsáveis pela construção de uma identidade de professor faltoso a representação de professor e de ensino/aprendizagem de inglês defasados é construída pela comparação entre o que é verificado no ensino público e no ensino em escolas de idiomas. Percebese que o elemento diferencial é enunciado como sendo a tecnologia, que aparece, primeiramente, de forma generalizada como "outros recursos" e, a seguir, como sendo, especificamente, o computador, a sala de vídeo e o retroprojetor. Esse aparato indicia o discurso das novas tecnologias na educação. Os "recursos" são generalizados como sendo "mecanismos de trabalho".

De acordo com Le Goff (2003), a imagem do professor na modernidade se associava a daquele que possuía uma certa posição de mestria. A suposição de saber no professor propicia que aqueles que demandam esse saber estabeleçam identificações e oposições ao objeto de saber em jogo, processos característicos do ensino/aprendizagem. Percebe-se, entretanto, no dizer de M, que o saber do professor é relativizado em função de fatores considerados externos ao docente e que, com a incidência do neoliberalismo na educação, influência marcadamente pós-moderna, se tornam mais valorizados socialmente, como os recursos tecnológicos, por exemplo ${ }^{6}$. Assim, os papéis de facilitador e de gestor, já amplamente alardeados como esperados dos docentes pela pedagogia pós-moderna e problematizados por Le Goff, parecem ser fortalecidos com o discurso das novas tecnologias, uma vez que a tarefa de ensinar não se encontra amparada na relação com o saber, mas com os recursos e com as habilidades que são tidos como possibilitadores desse saber (como apontado no tópico 3).

A professora parece esquecer, no entanto, que os recursos tecnológicos não são um fim em si mesmos, mas meios que possibilitam outras técnicas e a mobilização de uma outra linguagem que precisa ser apropriada para contribuir com o ensino/aprendizagem. $\mathrm{O}$ dizer da professora parece reforçar o peso que a tecnologia adquire na relação pedagógica, atribuindo à mesma um caráter indispensável.

Ademais, nota-se a subtração da dimensão mediadora do humano na relação com a máquina, conferindo ao ensino um caráter instrumental e técnico e ao professor o papel de operador da tecnologia. A indispensabilidade e a valorização da tecnologia emergem no dizer de M, produzindo o sentido de que a professora só se sentirá "segura" quando a tecnologia for implementada. Percebe-se, assim, o adiamento de uma tomada de posição como professora. De acordo com Coracini:

O efeito de naturalização das chamadas novas tecnologias, como base para um desempenho pedagógico de qualidade, instaura, no imaginário do professor, uma 
situação de conflito, despertando, ao mesmo tempo, o desejo de dominá-las e a angústia diante da constatação de seu desconhecimento e das dificuldades que colocam em xeque sua autoridade ou poder legitimado pelo saber que, embora lhe seja ainda atribuído pelo imaginário social, se vê questionado (Coracini, 2006, p.8).

O deslocamento do centro da relação pedagógica para os recursos tecnológicos parece favorecer uma desresponsabilização do professor de língua estrangeira do ensino regular público frente à posição que ocupa, uma vez que propicia a delegação da ineficiência do ensino à falta da tecnologia tida como necessária para o mesmo. Essa falta, portanto, soma-se às muitas outras que compõem a constituição identitária desse docente, tais como a falta de turmas adequadas, de salário compatível, de reconhecimento no cenário educacional (Baghin-Spinelli, 2002), dentre outras. Embora essas faltas sejam concretas no cenário educacional, elas nos parecem ser mobilizadas como uma das muitas desculpas para uma postura de acomodação frente à política de educação e ao ensino na rede pública.

Assim, não acreditamos que o problema esteja na falta em si. Afinal, no âmago da relação pedagógica encontra-se uma ação educacional que visa contribuir para a formação de indivíduos, bem como permitir a inserção dos mesmos em uma coletividade. Essa ação é reconhecidamente da ordem de uma utopia educacional (Cifali, 1994) e, portanto, atravessada pela incompletude. Nesse sentido, poderíamos pensar que a constituição identitária faltosa do professor de língua estrangeira do ensino público aponta, por um lado, para o desejo de estar sempre em busca de algo que permita a consecução da ação educacional, que se encontra no cerne de sua função de educador: o melhor método, as melhores técnicas, as inovações, o aprimoramento.

Todavia, nota-se no discurso do professor de língua estrangeira do ensino público uma insistência em denegar a falta, resistir a ela e, ainda, procurar tamponá-la, buscando implementar um processo de ensino/aprendizagem pleno e ser um professor "completo" baseado unicamente no que é considerado novo, moderno ou científico. No que diz respeito especificamente às tecnologias, elas se tornam verdadeiros gadgets no sentido que Lacan (1969-70/1992) delegou ao termo, ou seja, objetos de consumo produzidos e ofertados pela lógica capitalista e facilmente incorporados como se fossem objetos que poderiam anular a falta. Todavia, a falta é constitutiva do sujeito e, portanto, das relações entre eles, aí incluída a relação pedagógica.

Se ao professor de inglês faltam o saber e os "mecanismos de trabalho", como enunciado por M, o que resta ao professor ensinar e como ensinar, objetivo maior de sua posição na sociedade? Como assinalado acima, um dos efeitos do discurso das novas tecnologias no ensino/aprendizagem de línguas é que as mesmas são apresentadas como a solução de todos os problemas, representação discutida a seguir.

\section{5) $O$ caráter messiânico atribuído às novas tecnologias}


No dizer dos professores de inglês do ensino público é possível entrever a valorização atribuída às novas tecnologias contrapostas ao sentido de impossibilidade imputado ao ensino da língua nesse contexto. Vejamos os excertos seguintes:

\begin{abstract}
E02DP1
R- (...) então eu adotei todas as estratégias/ tipo/ primeiro chegava na sala né/ ficava falando pra todo mundo sentar abrir o caderno ou abrir o livro e tal né// Ah, não adianta// Aí eu adotei outra estratégia/ Eu falei/ bom eu vou entrar na sala e já vou dar o que fazer né// Então eu tchun/ entrava na sala e escrevia rapidinho alguma coisa pra eles fazerem// Também não funciona/ porque você passa a coisa na lousa/ como a sala é numerosa a explicação tem que ser quase individual/ pelo despreparo deles/ e pelo barulho/ dos alunos/ então assim querer explicar alguma coisa pra sala toda é bobagem// Tentar dar aula de listening né/ colocar o CD? Bobagem// Colocar vídeo? Eles não estão preparados eles não assistem// Tem sim/ tem meia dúzia que senta lá na frente e fica prestando atenção// Os outros ficam bagunçando bagunçando/ arrastando carteira/ quer dizer pra ouvir eles põe a televisão no máximo entende? E eles eh/ não conseguem// Então assim/ é difícil//muito difícil// Talvez/ eu imagino né/ que talvez/ o computador seja a solução// Aulas no computador/ mas imagina/ quando que o Estado vai ter isso?
\end{abstract}

E03DP1:

$\mathrm{R}$ - (...) mas então você vê assim/ como é que é o aproveitamento de um aluno que tem computador à disposição/ né/ inclusive nas aulas de inglês/ regulares/ nas aulas regulares eles tem acesso ao computador/ né/ eles têm o som/ coloca o fone/ cada um ouve no seu tempo/ ah/ tem uma professora lá esp...SUPER bem preparada/ né/ todos lá com pós-graduação/ com mestrado/ doutorado/ né/ doutorado não são todos mas mestrado com certeza/ então é uma escola que tem recurso etc./ como é que é o aproveitamento? eh/ eh o aluno que tem/ em casa/ o computador também à vontade/ tem acesso a revistas/ à TV a cabo/ tudo/ né/ vai pro exterior/ conhece a Disney/ etc/ eh/ como é que é esse aluno?/ e aí comecei a comparar com o Estado/ eu acho que pelos recursos/ o aluno do Estado ele é MUITO bom// porque/ né/ comparando/ o aluno do Estado não tem nada// nada//

Em E02, os marcadores discursivos "primeiro", "ẩ", "então" no dizer de R constroem não só uma ordenação sequencial que precede a descrição das ações tomadas pelo professor, mas também estabelecem uma relação de decorrência entre uma ação e outra, construindo a ideia de esgotamento de soluções. O dizer de R corrobora o sentido da evolução progressiva ilusória que é conferida aos recursos tecnológicos, que vão desde os considerados mais simples e, portanto, tidos como mais arcaicos e ineficientes - como a "lousa" e o "caderno" -, até o vídeo e a televisão, os quais são desvalorizados por serem tidos como ultrapassados em favor do "computador". Este, tomado como exemplo das novas tecnologias usadas no contexto pedagógico, é apresentado como sendo a possível solução diante das dificuldades enumeradas pelo professor. Novamente percebe-se que a posição atribuída ao professor vai sendo gradualmente evacuada em favor da máquina, à qual é reputada um papel praticamente messiânico perante o cenário caótico da sala de aula descrita.

O excerto seguinte (E03) é marcado pela comparação construída pela contraposição entre o aluno que tem acesso às novas tecnologias e à vivência com a 
língua (aqui materializada linguisticamente por meio das menções às viagens ao exterior) e o que não tem.

O ponto que queremos enfocar nesses excertos é a representação de ensino e de professor que é construída pela comparação entre o aluno da escola pública e o da escola particular, em que as turmas são representadas como menores, os alunos mais preparados e as salas de aula melhores equipadas. Observa-se um esvaziamento da imagem do professor no primeiro contexto de ensino, construído pela ausência dos recursos tecnológicos e pelo despreparo do professor, contrapostos ao tudo imputado ao ensino e aos professores da escola particular. Chama a atenção o adjetivo atribuído aos professores ("super") e a ênfase entonacional com que ele é enunciado, que remete à qualificação dos professores e aos recursos de que dispõem para dar aulas.

Esses mecanismos discursivos aliados à expressão "muito bom", igualmente enfatizada na enunciação para se referir aos alunos do ensino público, corroboram o efeito de ironia no dizer de R para qualificar o ensino, os alunos e os professores nesse último contexto. Em outras palavras, esses se associam ao "nada", enquanto os da escola particular possuem o todo pretensamente necessário para que o ensinoaprendizagem de língua se dê, contribuindo para a imagem desvalorizada, associada ao despreparo do professor de língua estrangeira do ensino público. O messianismo atribuído às novas tecnologias é produzido, assim, pelo caráter solucionista e pela completude a elas associados, traços do discurso da ciência ao qual elas se vinculam.

As novas tecnologias representam alguns dos muitos resultados de pesquisas científicas e, portanto, são discursivisadas como sendo uma significativa ferramenta na construção de uma sociedade eficaz. Enquanto elemento do discurso científico maior que permeia o discurso pedagógico sobre o ensino-aprendizagem de língua estrangeira, elas são objeto de uma mitificação característica do processo de apropriação e distribuição do conhecimento (Coracini, 2006).

A valorização do conhecimento científico e dos resultados por ele produzido decorrem do projeto centrado na racionalidade, reavivado no iluminismo e acirrado na modernidade. A ciência abalou o lugar de autoridade conferido à religião para responder às indagações do homem moderno, impondo-se como uma verdade tão sagrada quanto aquela que combatia. $\mathrm{O}$ principal objetivo do pensamento iluminista era alcançar um domínio científico por meio da razão, o que livraria a humanidade das imprevisibilidades do mundo natural e garantiria uma sociedade estável, democrática e igualitária. A busca pela eficiência até chegar, se possível, à perfeição constituía o cerne da ciência. Percebe-se, assim, que esta acabou por se impor não como um oponente ou rival da religião, mas seu possível (e desejável, para o projeto da modernidade) substituto (Lebrun, 2008).

Retomando o excerto 02, então, percebe-se que o caráter messiânico delegado às novas tecnologias se encontra respaldado no discurso da ciência, que se reveste de uma legitimidade calcada não na autoridade de um sujeito que enuncia, mas nos pressupostos 
da coerência científica. Lebrun (2008, p.95) ressalta que o saber científico se impõe como prescindido de mestres. As novas tecnologias são apresentadas, conforme assinala Coracini (2006, p.9), "como um pacote fechado, com o lacre da confiabilidade científica, como objeto de troca sem que ele [o consumidor] saiba como e porque elas foram concebidas e implementadas".

A modernidade é inaugurada, portanto, na esteira do discurso da ciência. O que se configura como positivista-vanguardista é associado à ideia de libertação do dogmatismo religioso e seu pretenso acanhamento racional. Daí a valorização do constante avanço tecnológico e de inovação para perseguir o progresso infindável, o que pode explicar a importância atribuída aos computadores como motivadores e solucionares dos problemas do ensino-aprendizagem de inglês, segundo o dizer de R.

Somos herdeiros dos pressupostos modernos, os quais fazem crer na representação de que, com o desenvolvimento da tecnociência, estaríamos enfim livres de todos os limites na pós-modernidade e, por isso, o vazio inerente à condição humana seria preenchido (Lebrun, 2008). Na relação pedagógica, tal ilusão é sustentada por meio de uma ação pedagógica baseada na fruição e no prazer, que, neste artigo, tem como instrumento o computador, como discutido no próximo tópico.

\section{6) As novas tecnologias a favor da sedução pedagógica}

Outro eixo temático que emerge dos dizeres do corpus de Tavares (2010) é a sedução presente na relação pedagógica, que pode se dar tanto no sentido de perpetuar a reprodução do saber sem que haja envolvimento subjetivo, como de envolver aquele que demanda o saber em uma relação em que o sujeito se implique com o objeto desse saber. Os dois modos de sedução não são excludentes. Entretanto, na pós-modernidade, verifica-se o predomínio do primeiro em virtude de uma lógica organizadora da sociedade orientada para o gozo ${ }^{7}$. Na relação pedagógica, a desvinculação do ensino de seu objeto de saber e a aprendizagem regulada pela aprovação e pela fruição constituem dois traços dessa lógica, conforme enunciados nos dois excertos seguintes.

\section{E04D2}

$\mathrm{R}$ - (...) É/ na escola pública é realmente assim/ é uma pena/ a gente não tem acesso/ eu acho que/ um vídeo é muito legal/ eh/ se a gente pudesse fazer alguns exercícios no computador/ porque só o fato de estar no computador/ não muda muita coisa/ às vezes o exercício é o mesmo que tá no livro/ mas só o fato de estar numa tela de computador/ eles já adoram/ e a gente não tem [o computador]/

E05D2

$\mathrm{P}$ - E você acha importante? Ou você/ eh/ qual a relevância dessa infra-estrutura/ do vídeo/ computador/ laboratório...

$\mathrm{R}$ - Eu acho que a gente poderia/ eh/ são outras formas que a gente teria de conquistar o aluno// né/ eh/ dizem né /na IES / a IES fala isso/ que o aluno não se interessa porque a aula não é interessante// eu já acho assim/ não é só isso/ são vários problemas/ então/ a aula é chata/ né/ ficar ali sentado/ realmente uma aula inteira e tal/ é/ vendo/ escrevendo 
tal/ pra eles não tem nada a ver/ pra eles não tem a ver com a vida deles/ agora/ também não tinha a ver com a minha vida/ e eu fiz isso/ por quê?

Em ambos os excertos, observa-se a ênfase conferida aos recursos tecnológicos em detrimento ao conteúdo ensinado e à relevância das atividades realizadas por meio deles. Note-se, também, o adjetivo associado ao ensino através das novas tecnologias e os resultados esperados deste ensino (E04): "um vídeo é muito legal", "só o fato de estar numa tela de computador/ eles já adoram", "são outras formas que a gente teria de conquistar o aluno". Os adjetivos aliados aos verbos "adorar" e "conquistar" corroboram o sentido de que o ensino se volta para a aprovação do aluno, amenizando a força e o peso do objeto de saber. Desse modo, parece não importar o quanto o professor saiba desse objeto, mas o efeito que as ações promovidas na sala de aula terão sobre os alunos. Acirra-se a figura do professor como um mediador e facilitador. A mediação, porém, não se dá entre o aluno e o saber, mas entre o aluno e o fazer, sendo que esse fazer deve ser necessariamente prazeroso e ter o aluno como o centro.

Arendt (1957/2000) comentou essa tendência na educação assinalando que a imagem do professor sofreu um deslocamento como resultado de uma formação pedagógica influenciada pela psicologia moderna e pelas doutrinas pragmáticas. $\mathrm{O}$ professor é alguém capaz de ensinar qualquer coisa, ou seja, suas ações contam mais do que aquilo que ele sabe. Subjacente a essa postura, está uma teoria de aprendizagem que se configura como uma outra tendência apontada por Arendt, ou seja, "não se pode saber e compreender senão por aquilo que se faz por si próprio", procura-se "substituir, tanto quanto possível, o aprender pelo fazer" (Arent, 1957/2000, p.34).

Somando às considerações de Arendt, Michéa (1999) ressalta que as principais ações do professor, nesse cenário, se dão em torno da distração, da animação e da facilitação do aprendizado, as quais teriam como consequência o empobrecimento da capacidade crítica e do pensamento. A tônica recai sobre a interação e sobre a democratização das opiniões, o que parece acenar para a cultura do "achismo", amplamente vigente nas escolas atualmente. O autor denomina esse ensino que incapacita os alunos a pensar e que os coloca a serviço da ordem estabelecida de "o ensino da ignorância", título da obra em questão.

Os professores, sob esse ponto de vista, se assemelham a animadores e promotores de atividades pedagógicas as quais, nem sempre, se relacionam ao ensinoaprendizagem do objeto de saber, como indiciado em E04 e E05. Na mesma direção, as aulas se desenrolam como um talk show cujo discurso segue o padrão da mídia e do showbusiness e o que impera é a revolução audiovisual e a adoção compulsória de novas tecnologias. A escola, por sua vez, acaba por se tornar um espaço acrítico, um local de lazer, no dizer do autor, como um parque de atrações escolares. Ora, se a ênfase na relação pedagógica recai no saber ensinar em detrimento do saber aquilo que se é demandado ensinar, se do aluno é esperada uma automia que sustente sua 
aprendizagem, a autoridade do professor é deslegitimizada, uma vez que ela se funda na suposição de que ele detenha o saber e este é praticamente anulado.

\section{Considerações finais}

É inegável a contribuição das novas tecnologias na expansão das percepções sobre o mundo, sobre a diversidade cultural e para a experiência de alteridade. Além disso, com o acesso ao mundo digital, verifica-se uma democratização do conhecimento, abrindo espaço para o desenvolvimento do letramento digital. As tecnologias facilitam o acesso ao mundo virtual, acarretando a reconfiguração de modos de relacionamento e de subjetivação. Consequentemente, verificam-se outras formas de comunicação, de representação do tempo e do espaço e de relação do sujeito com o mundo (Lévy, 1993).

A questão que procuramos levantar neste trabalho, no entanto, é que a adoção de novas tecnologias abalou as estruturas do mercado de trabalho, familiares e educacionais. Assim, "a globalização envolve uma interação entre fatores culturais, trabalhistas e econômicos, o que tem causado mudanças nos padrões de produção e consumo, os quais, por sua vez produzem identidades novas e globalizadas" (Hall, 1997, p. 20).

Perscrutamos no texto publicitário e no dizer de professores de inglês do ensino público o efeito do discurso das novas tecnologias sobre a constituição de sua identidade profissional. Percebemos que esse discurso se reveste de um caráter de indispensabilidade que evacua a autoridade do professor, relativiza o saber nele suposto e lhe confere papéis que se articulam com uma lógica pós-moderna. Nessa lógica, o conhecimento se liga ao fazer e ao produzir, praticamente ignorando-se o tempo, o investimento subjetivo e o saber que precisam ser mobilizados e investidos em uma relação pedagógica.

Percebemos que o discurso das novas tecnologias incide na constituição identitária do professor de línguas estrangeiras de modo a imputar-lhe funções mais próximas das demandas da globalização e do mercantilismo que das demandas educacionais. Cremos que o sucesso da interpelação de tal discurso na construção da identidade de professor de línguas se dá em função do apelo para a constante inovação e produtividade, imperativos inerentes à pós-modernidade.

Todavia, é preciso lembrar que aquilo que se apresenta como novo é, na maioria das vezes, uma figuração do antigo (Coracini, 2006); ou seja, as novas tecnologias não romperam com as práticas letradas consagradas pelas sociedades, como é o caso da leitura e da escrita, essenciais ao ensino de língua estrangeira, por exemplo. O que ocorre é a modificação e a potencialização dessas práticas. Semelhantemente, as novas tecnologias não deveriam representar uma técnica nova, mas uma dimensão a mais, uma 
parte do conjunto do jogo coletivo (Lévy, 1993), por meio do qual o homem se relaciona com o mundo.

A implantação de recursos tecnológicos não garante que essas práticas sejam desenvolvidas. Pelo contrário, acreditamos que elas se efetivem apenas se o professor investi-las subjetivamente e investir-se nessa posição. Caso o professor não se encontre implicado com o objeto de saber e em sua posição subjetiva, as novas tecnologias podem se delinear como um reforço na desabilitação crescente desse profissional.

\footnotetext{
${ }^{1}$ Agradecemos a leitura do Prof. Gilmar Martins de Freitas Fernandes.

${ }^{2} \mathrm{O}$ trabalho pesquisou a constituição identitária de professores de inglês da educação pública em formação contínua e contou com depoimentos, entrevistas e produções escritas de alguns participantes do programa. Os excertos aqui analisados são dos depoimentos e entrevistas cedidos pelos professores.

${ }^{3}$ Entendemos a subjetivação como um processo contínuo de relação com a alteridade, presentificada primordialmente pela linguagem, para que alguém advenha como sujeito (LEBRUN, 2010).

${ }^{4}$ Este recorte advém de um anúncio publicitário de uma escola de idiomas, disponível no site: http://www.yesuberlandia.com.br/interna.php?referencia=lousa , acessado em 14.05.2011.

5 'E' refere-se a excerto e 'DP1'/ 'DP2' referem-se a depoimento 1 e depoimento 2, respectivamente.

${ }^{6}$ A respeito da influência do neoliberalismo na pedagogia e no ensino de línguas estrangeiras, ver Amarante (1998) e Mascia (2002).

${ }^{7}$ A noção de gozo, neste trabalho, referencia-se na psicanálise lacaniana.

${ }^{8}$ IES se refere à instituição de ensino superior que ministrava o curso de formação continua aos professores participantes da pesquisa.
}

\section{Referências Bibliográficas}

AMARANTE, M. de F. S. A ideologia neoliberal no discurso da avaliação: excelência e o avesso da excelência. Campinas. 301fls. 1998. Tese (Doutorado em Lingüística Aplicada) - Instituto de Estudo da Linguagem, Universidade Estadual de Campinas, Campinas, 1998.

ARENDT, H. (1957). La crise de la culture. 5.ed. Paris: Gallimard, 2002.

BAGHIN-SPINELLI, D. C. M. Ser professor (brasileiro) de língua inglesa: um estudo dos processos identitários nas práticas de ensino. 2002. 210fls. Tese (Doutorado em Linguística Aplicada) - Instituto de Estudos da Linguagem, Universidade Estadual de Campinas, Campinas, 2002.

BAUMAN, Z. Identidade: entrevista a Benedetto Vecchi. Rio de Janeiro: J. Zahar, 2005.

BUZATO, M. E. K. Incluídos na periferia: linguagem e letramento na inclusão digital em contextos de periferia urbana. 2007. 248fls. Tese (Doutorado em 
Linguística Aplicada) - Instituto de Estudo da Linguagem, Universidade Estadual de Campinas, Campinas, 2007.

CASTELLS, M. "A era da informação: economia, sociedade e cultura". In: A Sociedade em rede. São Paulo: Paz e Terra, 2000. v. 1.

CIFALI, M. Le lien éducatif: contre-jour psychanalytique. Paris, FR: Presses Universitaires de France, 1994.

CORACINI, M.J. Pós-modernidade e novas tecnologias no discurso do professor de língua. São Paulo: Alfa, n.50, v.1, p.7-21, 2006.

DA SILVA, T.S.A. As práticas neoliberais no processo de ensino e aprendizagem de língua inglesa. 2011. 189fls. Dissertação (Mestrado em Linguística Aplicada) UNITAU, Taubaté, SP, 2011.

FOUCAULT, M. A Verdade e as formas jurídicas. 3. ed. Rio de Janeiro: NAU Editora, 2005.

GRIGOLETTO, M. Um dizer entre fronteiras: o discurso de professores e futuros professores sobre a língua inglesa. Trabalhos em Lingüística Aplicada, Campinas, v. 41, p. 39-50, jul./dez. 2003. 15.

HALL, S. Identidade culturais na pós-modernidade. Rio de Janeiro: DP \& A, 1997.

LACAN, J. (1969-70). O seminário livro 17: o avesso da Psicanálise. Rio de Janeiro, RJ: Jorge Zahar, 1992.

LEBRUN. J.P. Um mundo sem limite: ensaio para uma clínica psicanalítica do social. Rio de Janeiro: Companhia de Freud, 2004.

A perversão comum: viver juntos sem outro. Rio de Janeiro: Companhia de Freud, 2008.

LE GOFF, J.-P. La barbárie douce: la modernisation aveugle des entreprises et de l'école. 2. ed. Paris: La Découverte, 2003.

LÉVY, P. As tecnologias da inteligência: o futuro do pensamento na era da informática. São Paulo: Editora 34,1993. 
MASCIA, M. A. A. Investigações discursivas na pós-modernidade: uma análise das relações de poder-saber do discurso político educacional de língua estrangeira. Campinas, SP: Mercado de Letras/Fapesp, 2002.

MENEZES DE SOUZA, L. M. T. \& MONTE MÓR, W. Orientações Curriculares do Ensino Médio: Línguas Estrangeiras in Linguagens, códigos e tecnologias. Brasilia: MEC, 2006.

MICHÈA, J.C. L'enseignement de l'ignorance et ses conditions modernes. Paris: Climats, 1999.

SPARGO, T. Foucault e a teoria Queer. Tradução de Vladimir Freire. Rio de Janeiro: Pazulin; Juiz de fora: Ed. UFJF, 2007.

TAVARES, C.N.V. Identidade itine(r)rante: o (des)contínuo (des)apropriar-se da posição de professor de língua estrangeria. 279fls. 2010. Tese (Doutorado em Linguística Aplicada) - Instituto de Estudo da Linguagem, Universidade Estadual de Campinas, Campinas, 2010. 